\title{
Pemanfaatan Mailchimp Sebagai Trend Penyebaran Informasi Pembayaran Bagi Mahasiswa Di Perguruan Tinggi
}

\author{
Untung Rahardja ${ }^{1}$ \\ Eka Purnama Harahap ${ }^{2}$ \\ Sarah Pratiwi ${ }^{3}$ \\ Dosen STMIK Raharja ${ }^{1,2}$, Mahasiswa STMIK Raharja ${ }^{3}$ \\ e-mail: untung@ raharja.info ${ }^{1}$, ekapurnamaharahap@ raharja.info ${ }^{2}$, \\ sarah.pratiwi@raharja.info ${ }^{3}$
}

\begin{abstract}
ABSTRAK
Teknologi informasi berkembang makin pesat dan semakin banyak orang yang menggunakan untuk menyelesaikan suatu pekerjaan atau mendapatkan informasi penting, namun masih banyak yang belum dapat merasakan keuntungan dari penggunaan teknologi informasi karena penyebaran informasi belum tercakup baik. Penyebaran informasi biasanya masih dilakukan secara konvensional pasti akan memerlukan banyak kertas dan biaya hanya untuk memberikan informasi tertentu. Saat ini mayoritas pengguna gadget pasti memiliki email, email adalah media yang paling aman dan sangat mudah untuk saling bertukar file data atau hal pribadi lainnya, semestinya kita harus bisa memaksimalkan penggunaan fasilitas yang sudah ada salah satunya yaitu MAILCHIMP. Mailchimp merupakan tool digital marketing yang bisa menjadi trend baru dalam penyebaran informasi yang dapat menyebarkan informasi secara akurat, efektif dan efisien bagi semua kalangan. Dengan adanya Mailchimp sebagai media informasi online akan memudahkan mahasiswa dalam mendapatkan informasi yang diinginkan dan menjadi suatu trend baru di kalangan IT. Sehubungan dengan permasalahan yang ada peneliti menggunakan 2 (dua) metode penelitian yaitu Metode observasi dan metode studi kasus. Diharapkan dengan adanya metode penelitian ini, masalah yang ada dapat terselesaikan dengan baik dan menghasilkan implementasi yang bermanfaat bagi mahasiswa di Perguruan tinggi maupun kalangan luas.
\end{abstract}

Kata kunci : Informasi, Mailchimp, Trend

\begin{abstract}
Information technology is expanding rapidly and more and more people are using to complete a job or get important information, but many still can't feel the benefits of using information technology because information dissemination has't been covered well. Dissemination of information is usually still done conventionally it will require a
\end{abstract}

41 | Untung, Eka, Sarah - Pemanfaatan Mailchimp Sebagai Trend Penyebaran... 
lot of paper and cost just to provide certain information. Currently the majority of gadget users must have email, email is the most secure media and very easy to exchange data files or other personal things, we should be able to maximize the use of existing facilities one of which is MAILCHIMP. Mailchimp is a digital marketing tool that can be a new trend in the dissemination of information that can disseminate information accurately, effectively and efficiently for all circles. With Mailchimp as an online information media will facilitate students in getting the desired information and become a new trend among IT. In relation to existing problems, the researcher uses 2 (two) research methods that are observation method and case study method. It is expected that with this research method, the existing problems can be solved well and produce a useful implementation for students in universities and the wider community.

Keywords: Information, Mailchimp, Trend

\section{PENDAHULUAN}

Seiring perkembangan teknologi yang semakin cepat sebuah perguruan tinggi harus dapat menggunakan teknologi itu sendiri. Pada perkembangan suatu perguruan tinggi mempunyai tujuan akhir yang sama yaitu keberhasilan dalam mempertahankan kehidupan dalam bidang pendidikan, berkembang dan memperoleh hasil. Dalam mencapai tujuan tersebut di tentukan oleh beberapa faktor pendukung baik yang datang dari luar maupun dalam lingkungan perguruan tinggi, begitu juga dari sebuah perusahaan dalam penanganan masalah pengolahan data juga tidak terlepas dari perkembangan teknologi informasi. Kemajuan pada bidang teknologi informasi semakin lama akan semakin meningkat yang mampu memenuhi berbagai macam data terutama kebutuhan informasi dari pengguna. Kebutuhan akan kecepatan dan keamanan dalam penyampaian informasi dan akses data pun semakin canggih dan menjadi salah satu media pendukung hampir di seluruh aspek kehidupan termasuk perguruan tinggi, namun selain kebutuhan akan penyampaian informasi juga membutuhkan penyebaran informasi yang akurat dan tepat, dimana setiap perguruan tinggi selalu meningkatkan mutu dan kualitasnya dengan cara mengembangkan fasilitas yang tersedia pada perguruan tinggi yang dapat menjadi sarana dan prasarana yang dapat di gunakan oleh mahasiswa salah satunya yaitu penyebaran informasi yang dapat memudahkan mahasiswa dalam mendapatkan informasi yang cepat serta akurat.

Perguruan Tinggi Raharja merupakan salah satu institusi pendidikan yang bergerak di bidang teknologi informasi. Oleh karena itu, Perguruan Tinggi Raharja terus menerus melakukan peningkatan dan pengembangan baik berupa sistem pembelajaran kampus atau sistem pelayanan kampus yang telah ada pada Perguruan Tinggi Raharja. Itu semua demi kenyamanan dan kelancaran perkuliahan di lingkungan kampus dan merupakan fasilitas yang di terima mahasiswa dan dapat di gunakan mahasiswa berstatus aktif.

42 | Untung, Eka, Sarah - Pemanfaatan Mailchimp Sebagai Trend Penyebaran... 
Mailchimp yang telah digunakan di Perguruan Tinggi Raharja merupakan salah satu fasilitas yang di sediakan dari Rinfo. Jadi Mailchimp adalah Sebuah webservice yang menyediakan layanan untuk mengirimkan email dalam jumlah yang banyak ke pengguna email. Menurut yang dilakukan oleh I Yoga Sudharma (2015) berjudul Analisis Strategi Digital Marketing Brodo. Penelitian ini membahas mengenai strategi digital marketing yang dilakukan oleh Brodo. Brodo merupakan salah satu perusahaan startup fashion e-commerce yang meraih sukses dalam meraup penjualan. Brodo melakukan kegiatan pemasaran dan penjualan berfokus pada pemasaran digital / online, kegiatan digital marketing Brodo. Mailchimp biasa dimanfaatkan untuk menyampaikan informasi di Perguruan Tinggi Raharja baik seputar perkuliahan ataupun promosi kampus yang bertujuan mengajak untuk mahasiswa ikut serta dalam mempromosikan kampus kepada teman atau keluarga selain itu Mailchimp juga dapat digunakan untuk menyampaikan informasi pembayaran atau informasi penting lainnya, Tampilan Mailchimp yang menarik bukan hanya berisi tentang rangkaian kata namun gambar yang dapat menarik perhatian para pembaca untuk melihat informasi apa saja yang terdapat pada Mailchimp tersebut. Dengan demikian Mailchimp sangat berperan penting dalam perkembangan kualitas sistem pelayanan kampus khususnya bagi mahasiswa.

Untuk lebih luas memaksimalkan Mailchimp yang kini sudah ada di perguruan tinggi baiknya dalam penyebaran informasi menggunakan Mailchimp dijadikan sebuah trend masa kini yang dapat bermanfaat dalam menunjang fasilitas kampus salah satunya itu informasi pembayaran kampus. Mailchimp yang terbukti dan termasuk kedalam tool digital marketing yang sudah banyak tertera di Internet yang membantu para enterpreneur dalam menyebarkan informasi mengenai produk yang mereka tawarkan, maka Mailchimp sangat cocok dijadikan penyebaran informasi yang dulunya masih konvesional menjadi berbasis media elektronik.

Pada kenyataannya di zaman modern tidak semua menggunakan media elektonik, masih ada yang bertahan untuk tetap menggunakan cara konvensional. Penyebaran informasi yang sedang berjalan saat ini masih terlihat manual dengan menggunakan kertas, banner, formulir, spanduk dan lain sebagainya. Sehingga penyebaran informasi dengan menggunakan media elektronik ini masih belum maksimal dan berjalan efektif. Dengan demikian mahasiswa tidak mendapatkan informasi yang up to date seputar kampus dan menjadi bingung harus mencari kemana informasi yang mahasiswa butuhkan secara cepat di karnakan kurangnya keteresediaan tempat untuk mendapatkan informasi yang di cari.

\section{PERMASALAHAN}

Berdasarkan uraian diatas terdapat permasalahan yang ada di lingkungan perguruan tinggi. Resepsionis yang bisa di jadikan tempat awal mahasiswa mencari informasi namun akan sulit jika mahasiswa sedang tidak berada di kampus namun sedang membutuhkan informasi pada saat itu juga atau sedang tidak memungkinkan

43 | Untung, Eka, Sarah - Pemanfaatan Mailchimp Sebagai Trend Penyebaran... 
untuk datang ke kampus. Dalam menyebarkan informasi biasanya resepsionis akan menempelkan pada papan informasi, terkadang mahasiswa tidak menyadari bahwa ada informasi penting di papan informasi tersebut misalkan jadwal Seminar, jatuh tempo pembayaran atau informasi kampus lainnya hal tersebut kurang efektif mengingat saat ini teknologi sudah berbasis IT dan penyebaran informasi sudah menggunakan media elektronik. Sama hal nya informasi mengenai pembayaran yang kaitannya penting dengan mahasiswa, mahasiswa membutuhkan informasi pembayaran berupa jatuh tempo pembayaran, tanggal registrasi atau total pembayaran, seringkali mahasiswa masih harus bertanya melalui kasir yang tentunya harus datang ke kampus hanya demi mendapat informasi yang mereka perlukan. Penyebaran informasi yang masih sangat manual yaitu dari pihak kasir kepada mahasiswa itu dianggap masih kurang efektif karena mahasiswa yang tidak berada di kampus atau sedang berada di luar kota bingung bagaimana cara mendapatkan informasi tersebut tentunya akan sangat merepotkan.Namun saat ini perguruan tinggi sudah menerapkan informasi dengan menggunakan media elektronik, dengan begitu penggunaan kertas sudah dapat di minimalisir. Oleh karena itu dibutuhkan suatu tool marketing yang dapat menyebarkan informasi menggunakan media elektronik yang sering digunakan yaitu Mailchimp.

Setelah penulis menganalisa di perguruan tinggi, tool digital marketing Mailchimp masih belum berjalan secara efektif oleh sebab itu berdasarkan analisa dari kekurangan yang ada serta untuk memenuhi kebutuhan saat ini terdapat 3 (tiga) permasalahan, diantaranya :

1. Penyebaran informasi di perguruan tinggi masih manual

2. Belum Maksimal nya penggunaan Tool marketing dengan baik di perguruan tinggi

3. Implementasi tool marketing yang belum merata di perguruan tinggi.

\section{METODE PENELITIAN}

Dalam melakukan penelitian, peneliti harus lah mempunyai metode penelitian yang pastinya setiap peneliti mempunyai metodenya sendiri, Menurut Sugiyono (2013:2) metode penelitian merupakan cara ilmiah untuk mendapatkan data dengan tujuan dan kegunaan tertentu. Dengan adanya metode penelitian peneliti dapat mengumpulkan informasi atau data serta melakukan investigasi terhadap informasi yang telah didapatkan tersebut. Berikut adalah metode penelitian yang digunakan peneliti

\subsection{Metode Observasi}

Metode Observasi merupakan teknik pengumpulan data, dimana peneliti melakukan pengamatan secara langsung pada objek penelitian untuk melihat dari dekat kegiatan dan permasalahan yang sedang terjadi yang dilakukan dan sebagai pemecahan 
permasalahan. Metode observasi dapat diartikan pula sebagai pengamatan dan pencatatan secara sistematik terhadap gejala yang tampak pada subyek penelitian.

\subsection{Literature Review}

Literature review adalah serangkaian teori, temuan dan penelitian terdahulu atau sudah pernah ada yang di jadikan landasan kegiatan penelitian selanjutnya dalam menyusun kerangka pemikirian dari masalah yang sedang di teliti. Berikut adalah sumber literature review yang peneliti dapatkan :

1. Penelitian ini dilakukan oleh Kursehi Falgeti (2011) yang berjudul Tranformasi UKM ke Bisnis Online Dengan Internet Marketing Tools. Penelitian ini membahas salah satu upaya pemerintah, dalam hal ini Kementerian Koperasi dan PT UKM untuk mengenalkan dunia internet marketing ke UKM adalah memfasilitasi papan perdagangan di www.indonesian-products.biz. Upaya ini untuk mengidentifikasi UKM untuk melakukan transaksi online. Masih banyak aspek lain di dunia pemasaran internet yang bisa diketahui oleh UKM. Makalah ini akan membahas teknik dan alat biaya rendah yang dapat dimanfaatkan dalam pemasaran produk dan layanan UKM. Salah satunya adalah memanfaatkan alat dari Google.

2. Penelitian ini dilakukan oleh Aditya Hermawan dan Aniek Murniati pada tahun 2017 yang berjudul Designing Online Marketplace To Resolve Marketing Problem For Small and Medium Enterprises (SMEs). Penelitian ini bertujuan untuk merancang pasar online untuk memberikan solusi terhadap permasalahan yang dihadapi UKM dan UKM, kesulitan untuk memasarkan produknya secara online. Salah satu masalah yang dihadapi UKM adalah sulit memasarkan produknya secara online. Salah satu solusi yang kami berikan adalah dengan merancang pasar online untuk mengatasi masalah pemasaran secara efektif. Kami menemukan bahwa UKM telah berusaha memasarkan produknya melalui media sosial seperti facebook, twitter dan lain-lain. Selain itu, beberapa UKM juga memiliki website dan mengiklankan produknya melalui iklan online. Namun, banyak dari mereka yang tidak tahu bagaimana memasarkan produk secara online guna meningkatkan penjualan. Kami merancang pasar online untuk UKM berdasarkan konsep e-commerce untuk mengatasi permasalahan yang dihadapi UKM, pemasaran yang efektif. Desain pasar online dibuat dengan mempertimbangkan kebutuhan UKM serta kebutuhan pelanggan. Oleh karena itu, penelitian ini dilakukan terhadap UKM di Malang, Jawa Timur, Indonesia dan orang-orang yang sering melakukan pembelian secara online. Dengan adanya pasar online, UKM dapat meningkatkan penjualan sehingga meningkatkan keuntungan bagi UKM.

3. Penelitian ini dilakukan oleh S. Maryam, M. Hubeis, dan Maksum yang berjudul Efektivitas Penyebaran Informasi di Bidang Pertanian melalui Perpustakaan Digital (Kasus Pusat Perpustakaan dan Penyebaran Teknologi Pertanian). 
Penelitian ini dilakukan untuk mengetahui dan menganalisis efektivitas penyebaran informasi pertanian melalui Perpustakaan digital Karakteristik, aksesibilitas informasi dan intensitas komunikasi pengguna perpustakaan dan Korelasi variabel mereka dianalisis secara parsial atau simultan.Hasil penelitian menunjukkan karakteristik, aksesibilitas informasi dan intensitas komunikasi pengguna perpustakaan Bersama-sama tidak menunjukkan korelasi yang signifikan dengan efektivitas difusi pertanian melalui perpustakaan digital pada PT PUSTAKA Bogor. Artinya pengguna datang ke perpustakaan untuk mencari informasi apa yang mereka butuhkan, Namun korelasi yang terjadi antara karakteristik pengguna perpustakaan dan akses informasi ditunjukkan secara signifikan.

4. Penelitian ini dilakukan oleh Wiwin Sulistyo, Dian W Candra, 2014 yang berjudul Desain Sistem Penyebaran Informasi yang Efisien dengan Memanfaatkan Teknologi Informasi di Pemerintah Kota Salatiga. Penelitian ini membahas pentingnya sebuah informasi sebagaimana tercantum dalam UndangUndang Keterbukaan Informasi Publik No. 14 tahun 2008 di Pasal 1, ayat 1 menyatakan bahwa informasi adalah bukti, pernyataan, gagasan dan tanda yang mengandung nilai, makna dan pesan, data, fakta dan penjelasan yang dapat dilihat, didengar dan dibaca. disajikan dalam berbagai format kemasan dan sesuai dengan perkembangan teknologi informasi dan komunikasi secara elektronik atau non elektronik. Informasi menjadi sesuatu yang sangat penting bagi publik dan pemerintah untuk menciptakan kondisi pengungkapan informasi antara pemerintah dan masyarakat dan institusi. Informasi akan sangat berharga bagi publik berdasarkan tingkat kebutuhan masyarakat. Kebijakan sosialisasi, serta informasi kepedulian masyarakat harus dilakukan dengan baik. Oleh karena itu, dalam penelitian ini, klasifikasi dan penyebaran informasi yang digunakan oleh kota Salatiga yang mengacu pada Undang-Undang Keterbukaan Informasi Publik dengan memanfaatkan teknologi informasi. Perancangan Sistem Informasi dibangun untuk menyampaikan informasi yang terjadi di dalam / antar instansi pemerintah / swasta, masyarakat dan individu baik dalam hubungan vertikal maupun horizontal di Pemerintah Salatiga agar berjalan efisien, sehingga tidak ada penyumbatan dalam penyampaian informasi.

5. Penelitian berjudul Implementasi FGR (First Generation Resources) dengan menggnakan Mailchimp sebagai sarana informasi di Perguruan Tinggi oleh Qurotul Aini, Indri Handayani, Nuril Huda membahas mengenai penyebaran informasi. Proses tool digital marketing itu sangat penting dalam penyebaran informasi yang sangat berkualitas dan menarik. Di beberapa Perguruan Tinggi sudah menerapkan tool digital marketing. namun proses yang sebelumnya yang berjalan masih dalam ruang lingkup yang kecil. sedangkan yang membutuhkan tool digital marketing ini sangat banyak untuk menyebarkan informasi. dalam penelitian ini terdapat 3 masalah perihal konsep tool digital 
marketing. jalan keluar masalah ini adalah yaitu dengan menerapkan Mailchimp. tool digital marketing ini diharapkan bisa sangat berguna bagi para dosen ataupun mahasiswa/i dalam penyebaran informasi secara modern. Sangat diharapkan penyebaran informasi FGR (First Generation Resources) dengan menggunkan tool digital marketing yaitu Mailchimp dapat berguna di Perguruan Tinggi.

\section{HASIL DAN PEMBAHASAN}

Dalam merancang Mailchimp yang nantinya dapat di sebarluaskan harus terdapat informasi yang tertera secara jelas, akurat dan berguna bagi mahasiswa. Mailchimp akan di kiriman bisa disebut email campaign yang mana Mailchimp juga termasuk ke dalam fasilitas yang disediakan secara gratis oleh google. Tahap awal dimulai dari pembuatan Mailchimp, isi Mailchimp yang berupa informasi terkait dan sampai laporan status Mailchimp yang sudah disebarkan melalui email.

Berikut Tahapan lengkap penyebaran informasi pembayaran dengan menggunakan Mailchimp :

1. Tahapan awal Pembuatan Akun Mailchimp dan masuk ke dalam halaman login. Sebelum melakukan tahapan Log in pastikan sudah sign up di Mailchimp, terdapat tulisan "Create an account" untuk membuat akun baru . Mailchimp dapat di akses melalui email yang sudah dapat terhubung dengan fasiltas Mailchimp ini.

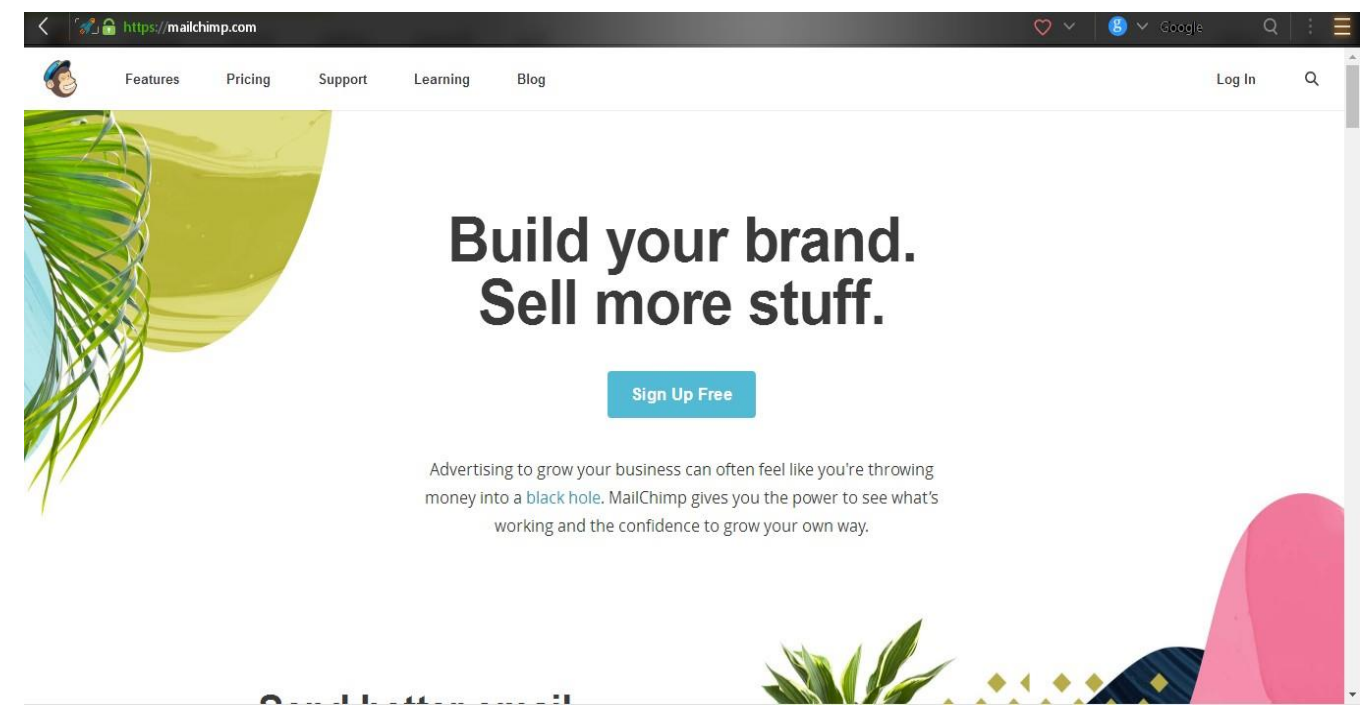

Gambar 1. Halaman Utama Mailchimp

47 | Untung, Eka, Sarah - Pemanfaatan Mailchimp Sebagai Trend Penyebaran... 
Dalam membuat akun baru harus mengisi kolom yang tersedia secara jelas dan benar, seperti nama email dan nama username serta password. Langkah awal pembuatan ini mudah sehingga semua kalangan dapat membuat akun Mailchimp.

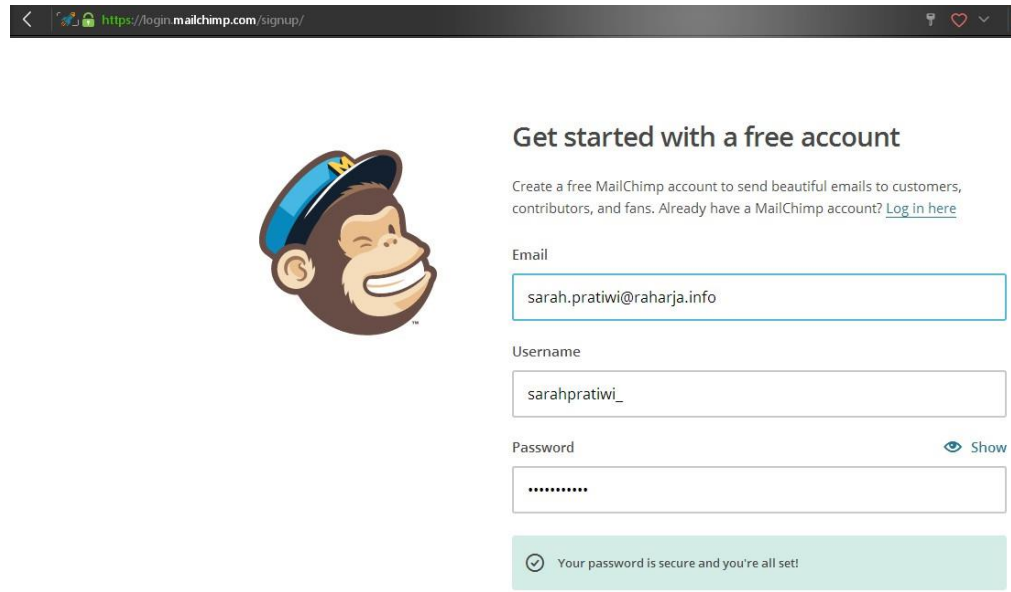

\section{Gambar 2. Halaman Sign Up Mailchimp}

Setelah akun berhasil di buat lakukan log in kembali untuk memastikan akun yang telah dibuat sudah aktif. Mailchimp berintegrasi dengan email jadi tidak harus khawatir, ketika lupa password akun Mailchimp ataupun mengalami kesulitan ketika melakukan Log in.

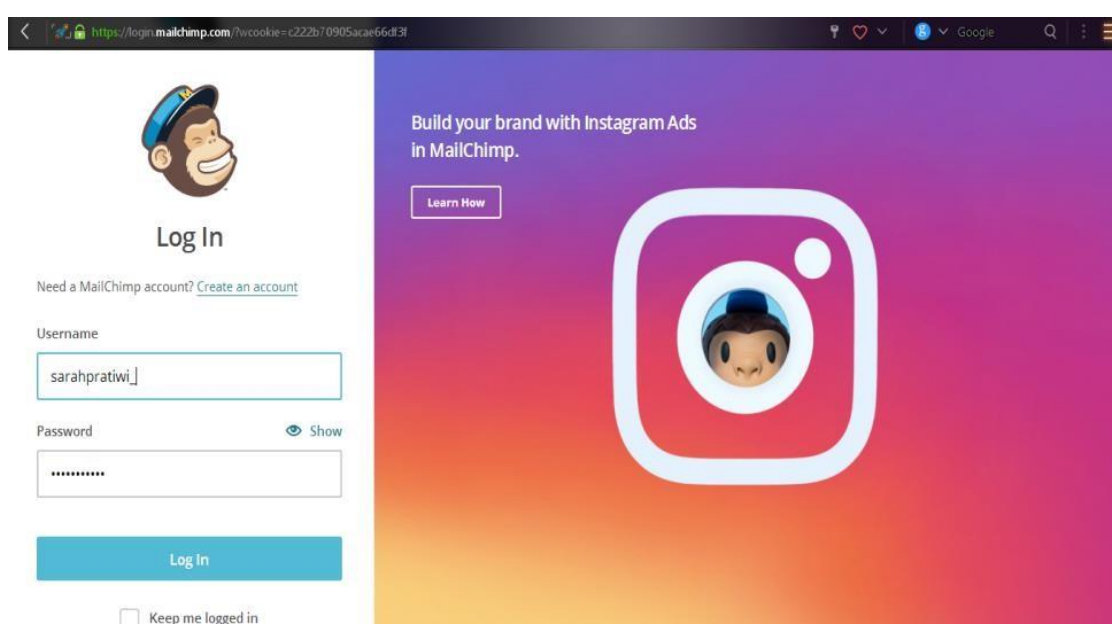

Gambar 3. Halaman Log in

48 | Untung, Eka, Sarah - Pemanfaatan Mailchimp Sebagai Trend Penyebaran... 
2. Halaman design campaign merupakan sebuah template yang di design terlebih dahulu sesuai yang di inginkan misalkan bisa ditambahkan foto (jpg, png, gif) dan alamat link yang akan langsung dapat menuju ke halaman yang di tuju. Hal yang harus di pastikan adalah template yang sudah di design sudah terdapat informasi terkait berserta petunjuk dan gambar untuk memudahkan penerima informasi sekaligus menarik penerima email Campaign untuk membuka email Campaign. Ini merupakan contoh template informasi pembayaran sudah dapat di akses melalui Aplikasi dan berisi ajakan untuk mengunduh dan juga terdapat link untuk mengunduh aplikasi tersebut dan tampilan semakin menarik dengan adanya foto atau gambar.

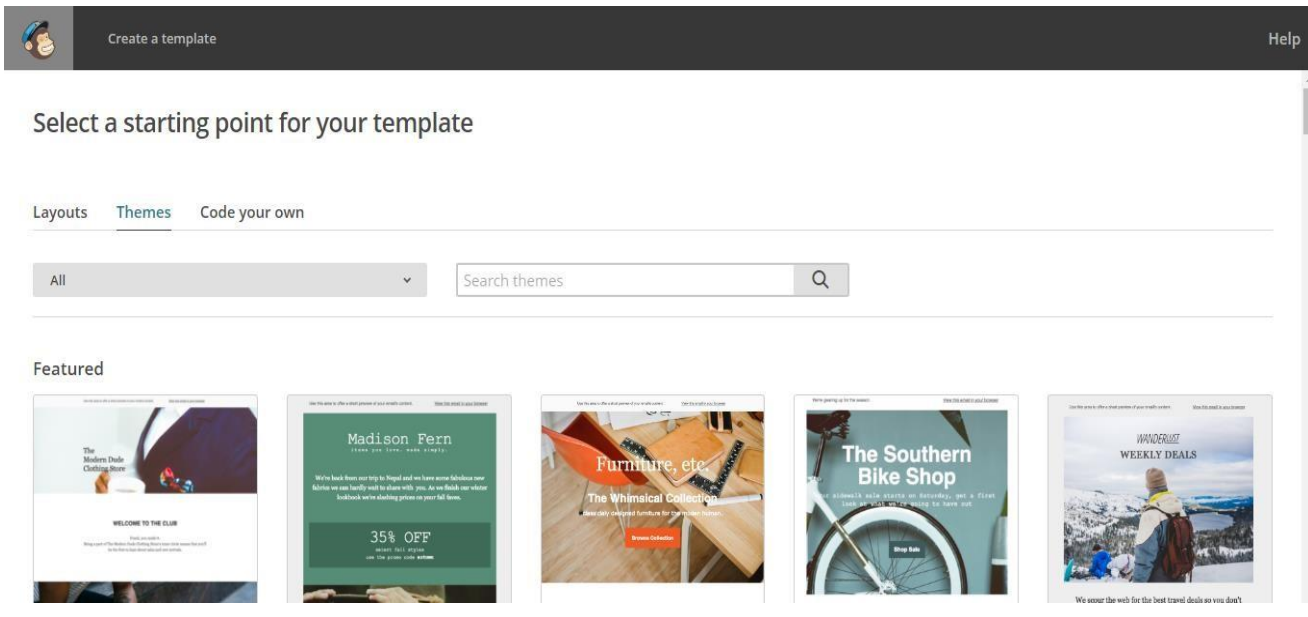

Gambar 4. Template Mailchimp

Dari template yang disediakan oleh Mailchimp juga dapat di design sesuai dengan kebutuhan ataupun kreatifitas pengguna. Mailchimp juga menyediakan untuk mengubah warna background, teks, menambahkan gambar, ataupun menghubungkan teks dengan link yang menuju ke halaman lain seperti website pribadi, blog pribadi dan website resmi sekalipun.

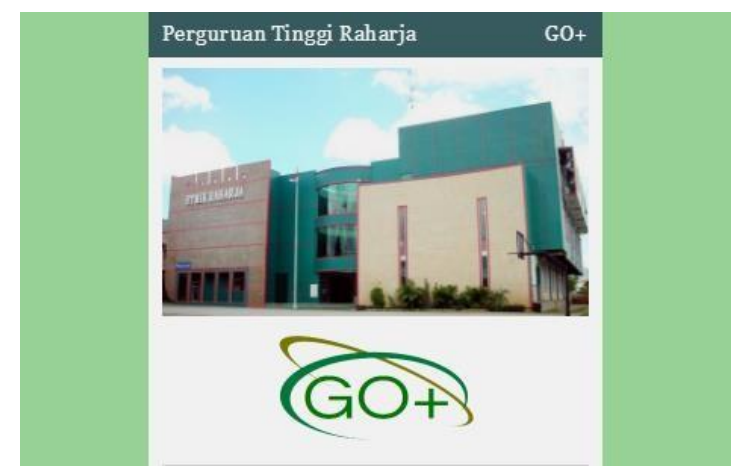

49 | Untung, Eka, Sarah-Pemanfaatan Mailchimp Sebagai Trend Penyebaran... 
Gambar 5. Template Mailchimp yang telah di design sesuai keperluan

3. Champaign Sent merupakan list email yang memuat daftar nama email si penerima email champaign yang telah berhasil terkirim. Ini berguna untuk mengetahui email mana saja yang berhasil terkirim dan tidak terkirim.

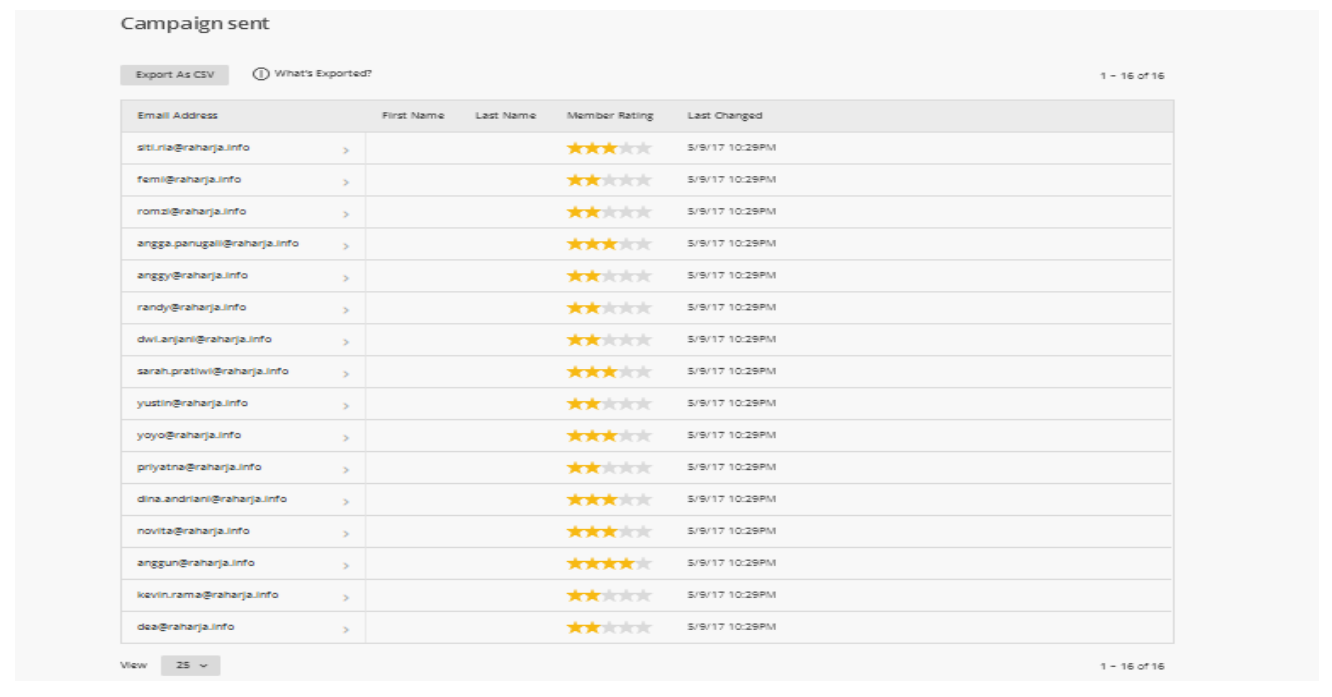

Gambar 6. Champaign Sent

4. Statistik performance adalah data email yang telah disebar ke banyak orang dapat tertera di dalam statistik perfomance terdapat jumlah perharinya dan perjam berapa yang telah membuka email Campaign tersebut. Ini berguna untuk melihat perkembangan email champaign yang telah dikirim sehingga ketika akan mengirim email champaign lagi terlihat perbedaannya. 


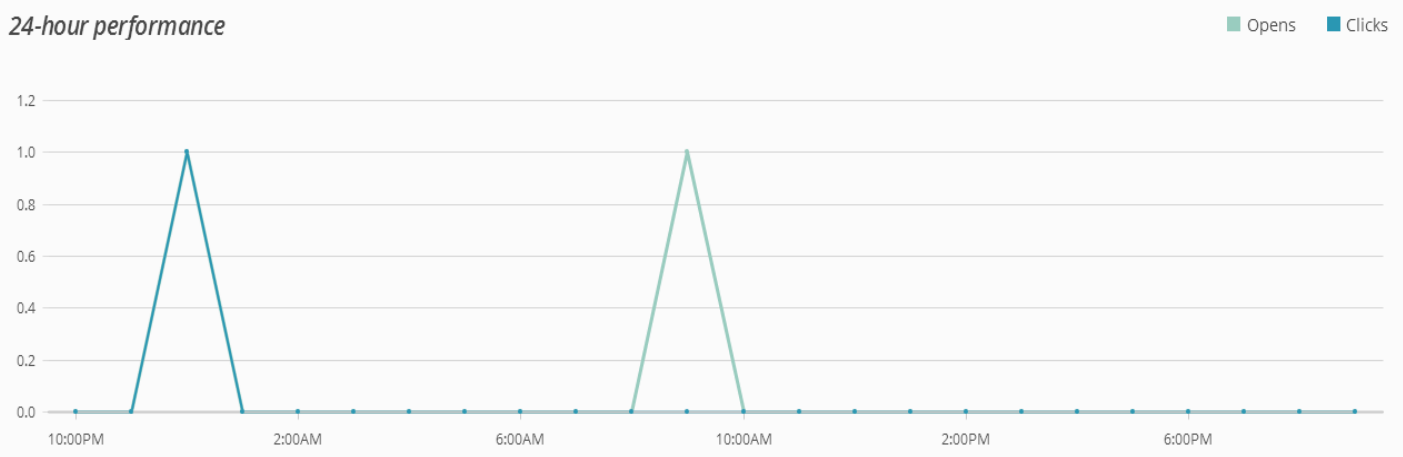

\section{Gambar 7. Halaman Performance}

5. Report opened adalah email yang sudah dikirim dan dibuka oleh si penerima email campaign yang telah dikirim tadi. Pada gambar berikut tertera list nama emailnya.

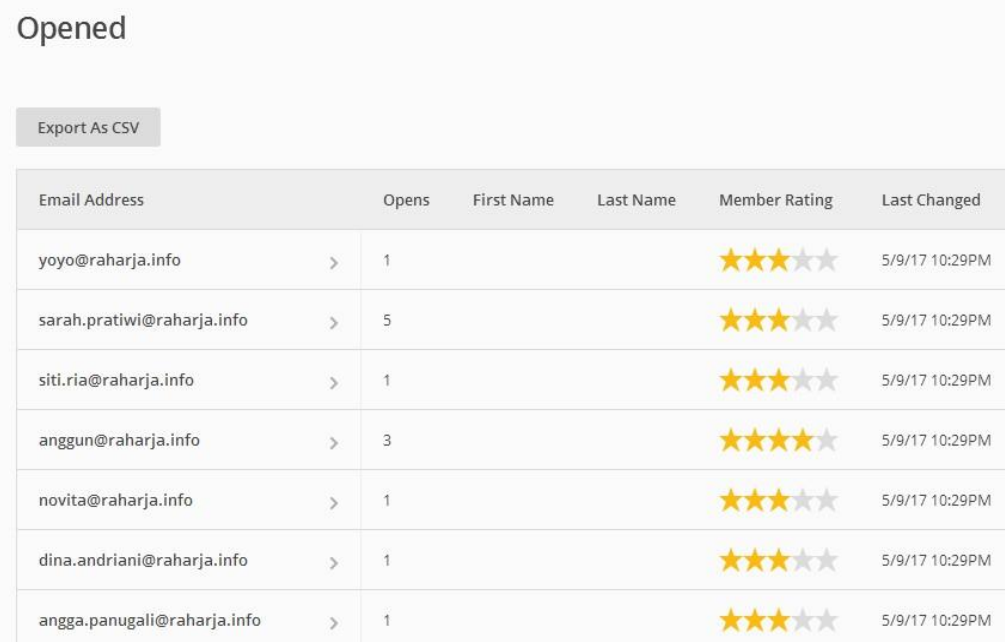

Gambar 8. Report Opened

6. Report clicked adalah list email yang sudah mengklik email campaign yang telah dikirimkan pada si penerima email. Berikut ini adalah list nama yang sudah mengklik atau telah membaca email champaign yang telah di kirimkan.

51 | Untung, Eka, Sarah-Pemanfaatan Mailchimp Sebagai Trend Penyebaran... 
Clicked

\begin{tabular}{|c|c|c|c|c|c|}
\hline Export As CSV & & & & & \\
\hline Email Address & & First Name & Last Name & Member Rating & Last Changed \\
\hline sarah.pratiwi@raharja.info & $>$ & & & 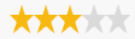 & 5/9/17 10:29PM \\
\hline anggun@raharja.info & $>$ & & & thtst & 5/9/17 10:29PM \\
\hline
\end{tabular}

Gambar 9. Report Clicked

7. Overview merupakan hasil report keseluruhan, uji coba pertama email dirimkan kepada 16 orang terdapat 13 yang telah open dan 7 orang dengan persentase Open rate $43.8 \%$ dan Click rate $12.5 \%$.

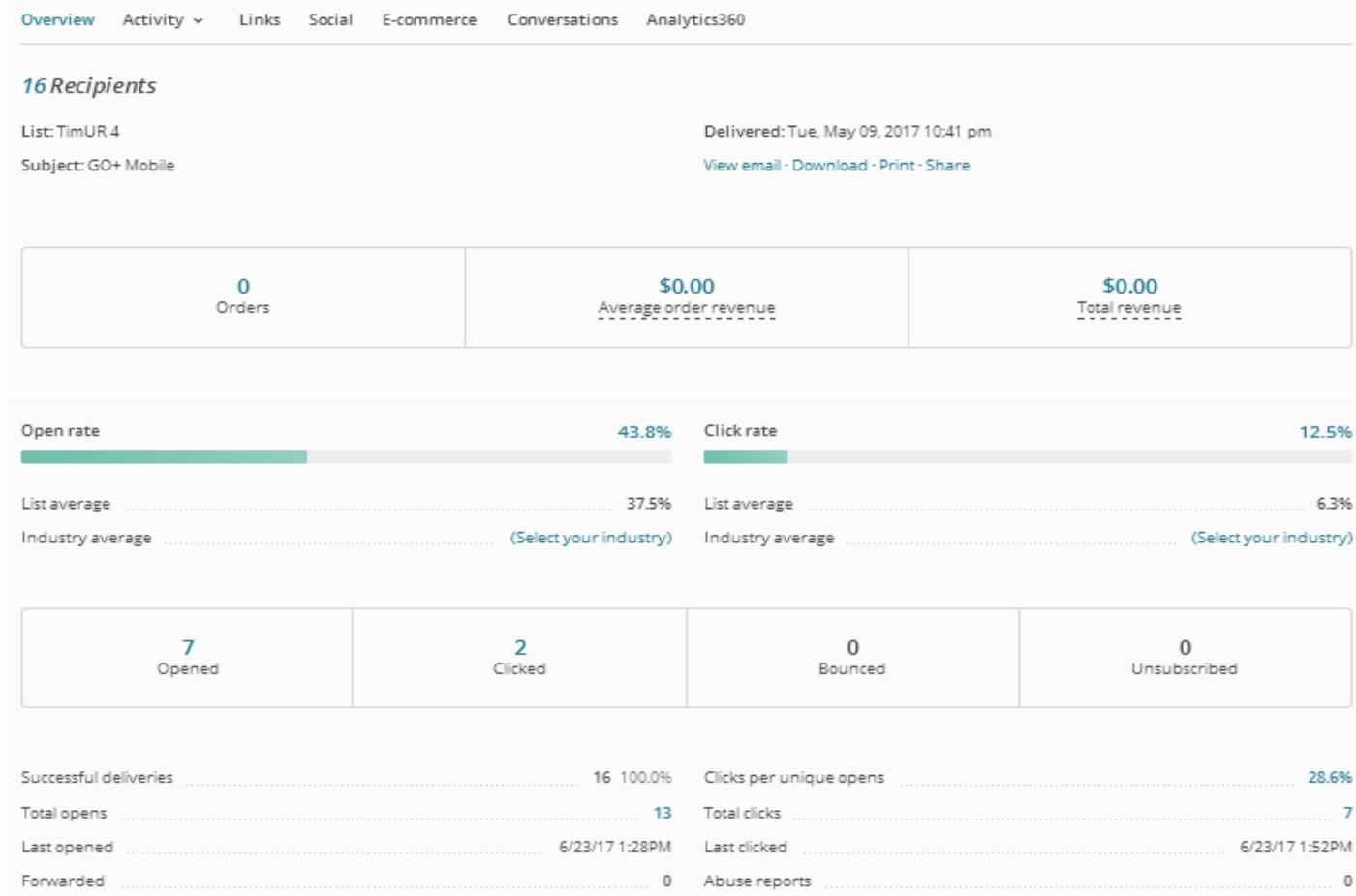

\section{Gambar 10. Overview}

Dari 7 uraian di atas dapat disimpulkan dalam dari email champaign yang telah dikirimkan ke 16 orang sudah ada 14 orang yang membuka dan 7 yang mengklik link informasi tersebut dan 2 orang lainnya tidak membuka maupun mengklik, dengan begitu Mailchimp benar-benar merekam semua jejak penerima email kepada si pengirim 
email champaign ini. Uraian di atas dapat di katakan sebagai hasil atau report dan Mailchimp pun menjadi laporan yang dapat dipertanggungjawabkan.Sehingga ketika melakukan penyebaran informasi menggunakan Mailchimp benar-benar tertuju kepada orang yang membutuhkan dan selain hasil report nya dapat menjadi sistem penunjang keputusan untuk kedepannya bisa mengembangkan dan menyempurnakan lagi.

\section{KESIMPULAN}

Tool digital marketing seperti Mailchimp ini dapat membantu dalam menyebarkan informasi seperti salah satu contohnya informasi pembayaran untuk mahasiswa, dengan menggunakan media elektronik ini memang sangat mudah dalam hal penggunaanya, mudah dipahami serta tampilan yang modern dan menarik. Diharapkan dengan menerapkan Mailchimp di perguruan tinggi akan menjadi bermanfaat bagi banyak orang serta membantu memotivasi untuk kedepannya menerapkan ke bidang yang lain sehingga Mailchimp pada akhirnya menjadi trend baru yang banyak di gunakan khalayak banyak. Namun Mailchimp mempunyai Kelebihan dan kekurangan yaitu Dapat di akses kapanpun dan dimana pun, dapat digunakan secara gratis dan user friendly.

Selain itu dengan adanya penelitian ini dapat disimpulkan bahwa pengguna Mailchimp dalam penyebaran informasi sudah menjawab 3 permasalahan yang telah ada yaitu :

Penyebaran informasi di perguruan tinggi masih manual beralih menjadi online atau menggunakan perantara media elektronik (tool digital marketing) yaitu Mailchimp, pengguna Mailchimp yang mudah dipahami dan membantu dalam pengiriman informasi melalui email dalam jumlah banyak. Peran Mailchimp yang sudah lengkap dan terbentuk dalam kemasan yang menarik mampu menggantikan peran kertas yang dahulu digunakan.

Penggunaan Mailchimp sudah mulai di gunakan bukan hanya untuk penyebaran informasi antar golongan tapi sudah mulai merambah ke bidang lainnya seperti informasi mengenai pendaftaran kampus sama informasi pembayaran.

Dengan adanya penelitian ini dapat memberikan pengetahuan mengenai Mailchimp, karena pada dasarnya Mailchimp bukan di gunakan hanya untuk kalangan perguruan tinggi namun bisa untuk kalangan luas. Diharapkan penelitian ini dapat memberikan pengetahuan mengenai Mailchimp yang mudah dipahami dan dapat di aplikasi kan pada bidang lainnya yang membutuhkan fasilitas atau media penyebaran informasi yang efektif, efisien dan akurat.

\section{SARAN}

Mailchimp yang kini sudah kian berkembang dan sudah mulai diterapkan di bidang promosi dan bahkan bidang pendidikan, akan tetapi masih memerlukan

53 | Untung, Eka, Sarah - Pemanfaatan Mailchimp Sebagai Trend Penyebaran... 
pengembangan lebih lanjut mengenai Mailchimp yaitu mengetahui bagaimana Mailchimp bisa digunakan dalam bidang yang lain yang kiranya sangat memerlukan Mailchimp dan bagaimana Mailchimp bisa di kembangan menjadi alternatif ataupun penganti media informasi yang masih kovensional misalkan brosur ataupun spanduk yang sering terlihat di depan umum juga bagaimana menimbulkan minat untuk membaca informasi yang ada dalam Mailchimp bagi khalayak umum.

\section{DAFTAR PUSTAKA}

[1] SUDHARMA, I. Y., \& Astuti, P. H. (2015). ANALISIS STRATEGI DIGITAL MARKETING BRODO (Doctoral dissertation, Universitas Gadjah Mada).

[2] Bandung, D. (2013). Metode Penelitian Pendidikan Pendekatan Kuantitatif, Kualitatif dan R \& D. Bandung: Alfabeta.

[3] Falgenti, K. (2015). Transformasi UKM ke Bisnis Online dengan Internet Marketing Tools. Faktor Exacta, 4(1), 62-73.

[4] Hermawan, A., \& Murniati, A. (2017). Designing Online Marketplace To Resolve Marketing Problem For Small and Medium Enterprises (SMEs). JEMA: Jurnal Ilmiah Bidang Akuntansi dan Manajemen, 14(01), 54-65.

[5] Maryam, S., \& Hubeis, M. (2009). Efektivitas Penyebaran Informasi di Bidang Pertanian melalui Perpustakaan Digital (Kasus Pusat Perpustakaan dan Penyebaran Teknologi Pertanian). Jurnal Komunikasi Pembangunan, 7(1).

[6] Sulistyo, W., \& Chandra, D. W. (2014). Desain Sistem Penyebaran Informasi yang Efisien ÿengan Memanfaatkan Teknologi Informasi di Pemerintah Kota Salatiga.

[7] Aini, Q., Handayani, I., \& Huda, N. (2016). IMPLEMENTASI FGR (FIRST GENERATION RESOURCES) DENGAN MENGGUNAKAN MAILCHIMP SEBAGAI SARANA INFORMASI DI PERGURUAN TINGGI. Technomedia Journal, 1(1), 11-19.s . 